\title{
1. Introduction to the future of intellectual property
}

\section{Daniel J. Gervais}

There have been and continue to be many efforts to reform IP law. Those efforts tend to go in one of two, somewhat opposite, directions. The first is to reform those IP laws that have been on the books for decades or more. These efforts to change the fundamentals of IP or its aspects that have deep historical roots are rarely successful (IP laws are rarely rewritten from the ground up) but they can shed new light on aspects of IP that can, in turn, inform other reform efforts. The second direction is to add rights beyond the historical core or primary IP rights.

The term primary IP rights can be used to refer to rights in copyright, trademark, design and patent law that have been part of both international treaties and many national laws for more than 50 years - in many cases for well over a century. Adding new rights to those primary rights instead of changing them produces secondary rights. The term 'peripheral rights' could also be used in this context. Adding secondary rights inevitably raises a number of questions, including what it means for primary rights. It has a number of important consequences. For example, secondary rights tend to be outside the definition of 'intellectual property' in the TRIPS Agreement, and they would thus not be subject to national treatment obligations under TRIPS.

Why do we need to add new rights to the primary rights? One example of a secondary right approach (in the field of copyright) is contained in the WIPO Copyright Treaty (WCT) and the WIPO Performances and Phonograms Treaty (WPPT). Those treaties added rights against circumvention of Technological Protection Measures (TPMs) and removal or alteration of Rights Management Information (RMI). Those rights are sometimes referred to as 'para-copyright'. Those treaties follow efforts in the 1950s and 1960s that led to the adoption of rights 'neighbouring on copyright' (now usually referred to as related rights) for performers, record producers and broadcasting organizations (and ultimately the 1961 Rome Convention). Then a sui generis right in databases was added to EU law. It seems fair to say that few efforts to create sui generis rights have met with complete success. 
In the field of trademarks, courts and legislators have added doctrines to traditional confusion-based tests. One example of such a doctrine is dilution in United States law. At the international level, there remains a vigorous debate about what should be the standard for protecting well-known marks. While the scope of patents and designs remains contentious internationally, these areas have seen adjuncts such as the now mostly defunct right in computer chips added to international IP law (including TRIPS). In the pharmaceutical area, patents and rights in clinical data (data exclusivity) provide overlapping and in some cases telescoping protection, with scant attention paid to their interaction.

It is not just rights. New exceptions and limitations have been added to primary rights (such as copyright E\&Ls for print-disabled users, and perhaps in the future libraries and archives). The availability and scope of these E\&Ls can be restricted, however, both by overlapping primary rights and by secondary rights. For example, a digital rights management (DRM) circumvention may prevent actual use of a copyright exception.

Discussing IP reform means, if one aims to be comprehensive at least, considering both reforms of primary IP rights and the impact of secondary rights on such reforms. This means looking both at the need to, and consequences of, changing primary IP rights, and whether adding secondary rights (with potential overlaps on primary rights) is a good idea, and if so when and how. There are intended and unintended consequences of changing primary rights, and of adding secondary rights or new E\&Ls.

Covering the entire topic of possible IP reforms would require an encyclopaedia. In this volume, which reflects some of the key contributions made at the 38th Annual Congress of ATRIP held in Nashville in August 2019, contributors address reforms on four specific themes. The first, and most general, theme is reforms of certain fundamental aspects of intellectual property (Part I). The second, is to consider the impact of a powerful exogenous force on IP, namely the emergence of artificial intelligence (AI) and its key input: data (Part II). Then specific reforms are discussed in respect of copyright and trademarks (Part III) and geographical names and indications (Part IV).

To open Part I, Phoebe Li proposes perhaps the boldest and broadest perspective on reform: A Manifesto on rethinking intellectual property 'for humanity'. Building on foundational work done, inter alia, by Professors Peter Drahos on the 'duties of privilege' and Peter Yu on the 'Yin-Yang' of IP, she proposes to redefine the nature of ownership through the lens of collective duties with a view to optimising the use of IP rights. This would reframe intellectual principles around development defined as 'a collective responsibility that needs to be human-centred' and uses the notion of 'Socially Valued Inventions'. She suggests 'practical means to better engage dignitarian approaches in the rights regime'. 
The analysis in the next chapter, by Roberto Garza Barbosa, provides an excellent illustration of the primary right-secondary right distinction mentioned above, as applied to pharmaceutical patents in Mexico. His detailed discussion of changes to Mexican legislation post TRIPS and the USMCA (or 'new NAFTA') and their repercussions at the Mexican IP Office (Instituto Mexicano de la Propiedad Industrial) and judicial bodies, including the Specialized Chamber on Intellectual Property of the Federal Court of Administrative Justice is illuminating in several ways. It suggests that much remains to be done to fully discuss the matter in Mexico and achieve an optimal balance.

Janice Denoncourt's chapter sheds light on a topic not sufficiently studied, namely how the framework of company law can inform and lead to a recalibration of the accountability of corporate intellectual property rights owners. The nature of the owner can influence, and change, the use and meaning of intellectual property. Her principal focus is on UK law but the lessons she draws can be useful in other jurisdictions. She suggests that it may be time to build a new taxonomy of different types of corporate IP owners, including the distinction between private and public companies, and the role of subsidiaries. One of her many important points is that 'some corporate IPR owners will resist the transparency train, opting for opacity to protect intra-group transfer mispricing or tax avoidance which usually comes to light when the business fails and becomes insolvent, potentially giving rise to risks such as company director disqualification'.

Emmanuel Oke tackles the increasingly important role of investment law in intellectual property, and its potentially transformative impact. Building on the work of, inter alia, Susy Frankel and Rochelle Dreyfuss, he argues that IP law and investment law must be synchronised. This requires revisiting the notion of protected 'investment' and the idea that '[m]erely registering or acquiring an intellectual property right in the host state without more' is sufficient. He suggests that '[i]t is only when an investor exploits its intellectual property right through, for instance, the commitment of resources into local manufacturing and sales that it can contribute to the economic development of the host state'.

Professor Abbe Brown's excellent contribution closes Part I but also marks the transition to Part II (AI and data). She uses oil and gas as the canvas to paint her chapter but notes in her very first sentence that '[d]ata is the new oil'. Looking at litigation in a number of different jurisdictions, she explicates how 'decision makers in respect of oil and gas regulation and legislation and in respect of IP law are in fact taking a blinkered, or at least incomplete, approach to addressing this apparent battle' between the interests of IP owners and public goals, such as responses to climate change and public health. As she rightly notes, a better understanding of this interface and potential under- 
lying conflicts 'can have an impact on all regulatory and legislative actions to address a public goal when the response (properly viewed) involves more than one policy area and field of law, and also involves private rights'.

Part II on AI and data opens with a chapter by Dan Burk, who expresses healthy scepticism about the emergent properties of AI systems to invent like humans. As he puts it, "[a]sserting that AI tools are either inventors or infringers is equally absurd, and can only be based on ignoring the human hand at work behind the AI. Such algorithms, far from operating consciously or even autonomously, constitute tools that are deployed by researchers in order to design and develop new inventions'. Raising the question whether a machine could invent, however, poses questions seldom explored in patent law on the actual process of invention (and, downstream, the link between that process and ownership of the output). Beyond inventorship, his chapter discusses the application of inventiveness/obviousness, disclosure and claiming and infringement.

The four co-authors of the following chapter, Xiang Yu, Runzhe Zhang, Ben Zhang and Hua Wang, present a different perspective on the same topic as Professor Burk but also extend the analysis to copyright law. Their chapter draws a distinction between current (weak) and future (strong) AI. Their chapter explores the patentability of AI related and AI created inventions and various related doctrine, and the impact of infringement. They then turn to copyright law and analyse the role of $\mathrm{AI}$ in the creation of new works, and the impact on ownership and licensing. Their chapter discusses a number of possible avenues that legal systems might take, such as a 'public property' approach to AI inventions and works, a new neighbouring right, or new sui generis right for AI created inventions and works, and possible smaller scale adaptations to the current framework.

Margaret Ann Wilkinson's rich contribution stems from a Canadian perspective but offers a most useful take on the interface between IP and competition law. She discusses para-copyright rights and data exclusivity in various trade agreements. Her detailed analysis of the interface between primary (copyright and patent) and those secondary rights illuminates the tension and different nature of both. She draws an important conclusion from this analysis, namely that these secondary rights 'are not IP mechanisms because there are no incentives to make information public - rather there are legally imposed barriers to doing so. None of the three shares the characteristics that patent and copyright have in common: none of the three are limited term monopolies designed to bring ideas into the public realm'.

The next chapter, by Helen $\mathrm{Yu}$, in a way continues the analysis. Her contribution puts the spotlight on 'black box medicine' which she defines as 'a predictive model that leverages the processing power of computer systems to discover patterns in data and suggest results or recommendations without 
explicit knowledge or explanation to justify the output'. With a focus on Canadian law, she discusses the application of the disclosure requirement in patent applications in this field, and the need to demonstrate the utility of those inventions, and specifically the doctrine of sound prediction. She concludes that:

[b]ecause black box medicine will be relied upon to make critical predictions, there is an increasing demand for transparency, not only to ensure the predictions are justifiable, legitimate, or supported by understandable explanations, but also because this type of information is required to satisfy the utility and sufficiency requirement to seek patent protection for these algorithms.

Part III applies some of the rethinking ideas centred on the primary/secondary right distinction to copyright and trademark law. The Part opens with a chapter by Giuseppe Mazziotti that bridges Parts II and III and suggests a data-driven approach to copyright at a time when much if not most copyright content is accessed through a handful of global, scarcely regulated platforms. Those platforms, which have re-intermediated 'content' distribution, have 'extensive knowledge of their subscribers' preferences', which they can use 'to target commercial offerings at a single user'. This tends to 'exacerbate pre-existing inequalities in exposure, success and distribution of music works and disparities in income related to different genres and repertoire'. To ensure better remuneration for creators, the chapter argues for more access to the platforms' and CMOs' secret data ('black boxes').

Then Bukola Faturoti takes a detailed look at the 'many sins' of the CJEU's judgment in Land Nordrhein-Westfalen $v$ Dirk Renckhoff and discusses the impact it had or may have on the 'relationship between copyright and the right to education and how the teaching and educational exception could preserve this right'. The judgment, which adopted an expansive view of copyright rights, 'poses more new questions instead of providing the answers it was expected to supply'. By failing to focus appropriately on the educational purpose of the use (use by a pupil for school presentation followed by posting on a school website of a publicly available photograph), the CJEU 'has left the right to education gasping for recognition in the virtual environment'.

The next chapter is on a related topic. Ivana Kunda examines hyperlinking under EU copyright law. Her detailed analysis of CJEU caselaw shows inconsistencies concerning the right of communication to the public which in turn have led to different approaches by courts in EU Member States. The application of the theory of an implied license for online material depends for example on a series of policy factors. She argues in that context that the link 'between the right of communication to the public and the underlying functions of copyright - in particular the communication (dissemination) function $[\ldots]$ is 
highly underappreciated in the scholarly discourse'. One of her conclusions is that current EU law as interpreted by the CJEU 'threatens the interests of all stakeholders and may encourage opportunistic behaviour and have a chilling effect over the freedom of expression and information'.

Part III ends with a contribution by Guillermo Martínez Cons on the modernisation of trademark law in Mexico, and specifically the protectability of olfactory and sound marks. The chapter is useful in several respects. One of them is that it provides the reader with an understanding of the IP reform and legislative process in Mexico, a situation that is likely similar in a number of other jurisdictions. It also situates IP within the broader Mexican legal system. It concludes that 'the registration of olfactory and sound trademarks is technically defective, due to the notorious lack of clear and understandable rules that allow to determine in an objective way that a trademark is distinctive, aggravated by the absolute lack of rules of confrontation'.

Part IV focuses on an area of intellectual property that seemingly keeps expanding though its progression has been slow. The protection of names of countries and other geographical areas in relation to the sale of various products (and in some cases services as well) remains understudied, however, when compared to its IP cousins. The Part offers two useful contributions that should help narrow this gap. First, Bernardo Calabrese turns the spotlight on what some see as the very core of the GI system, namely a product's reputation, he suggests we 'abandon the fallacy of reputation, which does not in itself found this IP right, and to restore consistently the regime of GI around what lies beneath reputation'. Using his deep knowledge of the subject-matter, he shows that:

on the side of consumers' interest, GI pursue a certification function in terms not only of origin but also of quality, which however is apparently missing in case of mere reputation, compromising the role and credibility of this special category of public distinctive signs; moreover, concerning preservation of local enterprises, reputation entails a loosening of the territorial requirements that could drift the system towards a wider degree of delocalization.

He suggests that GI law could borrow a page from plant variety protection to move beyond reputational factors.

Finally, Natalie Corthésy allows this volume to sign off most pleasantly with love from France. She asks 'whether a State should have an exclusive right to use its name, and safeguard it against abuse when others seek to use it in trade'. She introduces the notion of 'argotisation' (borrowed from both the Greek 'argo' for swift and the French 'argot' for slang). She uses it to encapsulate 'behaviours encompassed by unfair competition in the strict sense, as well as unfair competition in the extended sense'. She suggests introducing a right 'that inures to the benefit of all sovereign States to exclusively control the use 
of their country name in commerce where it is used as a guarantee of origin, as well as a negative right to safeguard it against abuse'. 